\title{
Kompozit Perde Duvarların Yatay Yük Etkisi Altındaki Davranışlarının İrdelenmesi
}

\author{
${ }^{1} \mathrm{M}$ Nadir Olabi, ${ }^{* 1}$ Naci Çağlar, ${ }^{2}$ Mehmet Haşim Kısa ve ${ }^{3}$ S. Bahadır Yüksel \\ ${ }^{1}$ Mühendislik Fakültesi, İnşaat Mühendisliği Bölümü Sakarya Üniversitesi, Turkey \\ ${ }^{2}$ Mühendislik Fakültesi, İnşaat Mühendisliği Bölümü Karabük Üniversitesi, Turkey \\ ${ }^{3}$ Mühendislik ve Doğa Bilimleri Fakültesi, İnşaat Mühendisliği Bölümü Konya Teknik Üniversitesi, Turkey
}

\begin{abstract}
Özet
Son yıllarda birçok araştırmacı, sismik yükler altında daha iyi yapısal performans açısından konvansiyonel betonarme perde duvarların yerine kompozit perde duvarlar üzerinde çalışmaktadır. Kompozit perde duvarlar yapısal taşıyıcı sistem olarak; arttırılmış yanal yük kapasitesinin yanında mimari olarak dar kesitler kullanılmasına olanak sağlaması açısından tasarımcıların tercih ettiği sistemler haline gelmiştir. Bu konu kapsamında araştırmacılar genellikle hazır profil olarak temin edilebilen yapısal elemanları tercih etmişlerdir. Bu çalışmada hazır profil kesitleri yerine L kesitli çelik levhalar kullanılarak, 1/3 ölçekli, kompozit bir betonarme perde duvar oluşturulmuştur. Oluşturulan kompozit betonarme perde duvar yanal kuvvetler altında Selçuk Üniversitesi deprem laboratuvarında incelenmiştir. Kompozit betonarme perde duvarın sayısal modeli OpenSees sonlu eleman programı ile oluşturulmuş ve modelin doğrulanması deney sonuçları ile yapılmıştır. Deney sonuçları ile doğrulanan sonlu eleman modeli kullanılarak parametrik bir çalışma yapılmıştır.
\end{abstract}

Anahtar kelimeler: Kompozit betonarme perde duvar, sismik yük, sonlu eleman, OpenSees.

\section{Investigation of Composite Shear Walls Behaviour under Cyclic Lateral loads}

\begin{abstract}
During the last years many researchers have been working on using composite shear walls instead of conventional reinforced concrete walls to achieve a better structural performance under seismic loading. In addition to the increased lateral load capacity of composite shear walls, it becomes a preferred option to the designers in terms of allowing the use of smaller sections. However, researchers generally choose ready profiles for the composite shear walls. In this study, L-shaped steel plates was used instead of ready profiles, and 1/3 scaled composite shear wall was constructed at examined under lateral forces at Selçuk University, Earthquake laboratory. Numerical modeling of the composite shear wall was done using OpenSees finite element program and validated depending on the test results. A parametric study was conducted using the corrected finite element model.
\end{abstract}

Key words: composite concrete shear walls, earthquake load, finite element, OpenSees.

*Corresponding author: Address: Faculty of Engineering, Department of Civil Engineering Sakarya University, 54187, Sakarya TURKEY. E-mail address: caglar@sakarya.edu.tr, Phone: +902642955752 


\section{Giriş}

Deprem tehlikesi altındaki birçok yerle birlikte ülkemizde de depreme dayanıklı yapılaşmanın gerçekleşmesi mecburi bir gerekliliktir. Depreme dayanıklı yapı tasarımı az katlı yapılardan daha çok; yüksek katlı yapılarda daha da fazla önem kazanmaktadır. Bunun yanı sıra, son dönemlerde projelendirilen yapıların deprem sonrası hasar dağılımına bakıldı̆̆ında ise birçoğunun statik projelerinde oluşan hesap hatalarından değil de; projenin uygulaması esnasında çıkan zorluklar sebebiyle uygulanamamış proje detaylarından kaynaklandığı görülmüsstür. Bu tür problemlerin daha sık olarak karşılaşıldığı yapılar genellikle yüksek katlı yapılardır. Bu yapılarda deprem etkisinde yapının yüksekliğinden kaynaklanan aşırı moment etkileri doğmaktadır. Bu momentleri güvenle taşıyabilecek elemanlar genellikle perde elemanlar olarak tasarlanmaktadır. Perde elemanlarda statik olarak büyük önem arz eden perde uç bölgeleri, kolon benzeri bir eleman olarak tasarlanarak oluşan momentin ve normal kuvvetin karşılanmasında görev almaktadır. $\mathrm{Bu}$ tür yapılarda mimari kısıtlamalar sebebiyle dar kesitli ve farklı geometrik şekillerde oluşturulan perde uç bölgelerine yoğun donatı yerleştirilebilmektedir. Bu donat1 yoğunluğunun fazla olması sebebiyle uygulama esnasında dökülen beton tam olarak yerleştirilememektedir. Bu sebeple perde en kesitinin en çok zorlandığı kesitte dayanım yeterince sağlanamamaktadır. Düşey donatının yoğunluğundan dolayı aderans da bu bölgede yeterince gerçekleşemeyecektir. Uç bölgelerde yoğun düşey donatının yanında enine donatının sıklaştırılması gerekliliği de uygulama zorluklarının ortaya çıkmasına sebep olmaktadır. Son yılarda yapılan birçok çalışmada bu sorunların çözümüne yönelik farklı uygulamalar önerilmiştir [1-12]. Bu çalışmalarda perde uç bölgelerinde boyuna donatı kullanılması yerine boru, kutu ve $\mathrm{H}$ kesitli profillerle birlikte perde duvar kesitlerinin çelik levhalarla sargılanması da önerilmiştir.

$\mathrm{Bu}$ çalışmada L kesitli çelik saç levhaların kullanıldı̆̆ davranışı araştırılmıştır. Çalışmanın ilk aşamasında kompozit betonarme perde duvarın davranışı deneysel olarak ikinci aşamada ise sayısal model üzerinden incelenmiştir. Kompozit betonarme perde duvarın sayısal modeli OpenSees sonlu eleman programı ile oluşturulmuş ve modelin doğrulanması deney sonuçları ile yapılmıştır. Deny sonuçları ile doğrulanan sonlu eleman modeli kullanılarak parametrik bir çalışma yapılmıştır.

\section{Deneysel Çalışma}

$\mathrm{Bu}$ çalışmanın ilk aşamasında kompozit betonarme perde duvarın tersinir yüklemeler etkisi altındaki davranışı deneysel olarak araştırılmıştır [12]. Deney numunesinin kesiti $100 \mathrm{~mm} \times 1000 \mathrm{~mm}$ ve yüksekliği $3300 \mathrm{~mm}$ olarak seçilmiştir. Perde duvar uç bölgelerinde 4 adet L kesitli 23x69x $5 \mathrm{~mm}$ boyutlarında çelik saç levha kullanılmış ve $\phi 8$ 'lik etriyeler $7.50 \mathrm{~cm}$ aralıklarla bağlanmıştır. Yatay gövde donatıları $15 \mathrm{~cm}$ aralıklarla uygulanmış ve boyuna donatılar $\phi 10^{\prime} l u k$ seçilmiştir (Şekil 1-2). Kompozit perde duvarın ankastre mesnet koşullarını sağlaması için perde duvar ile güçlü döşeme arasındaki bağlantı rijit davranış gösterecek temel kullanılarak sağlanmıştır. Numunenin oluşturulmasında $25 \mathrm{MPa}$ dayanımı sağlayacak hazır beton kullanılarak deney elemanı teste hazır hale getirilmiştir. Rijit temel-güçlü döşeme, yükleme düzeneği-güçlü duvar bağlantılarında bulonlu birleşimler tercih edilmiştir. 


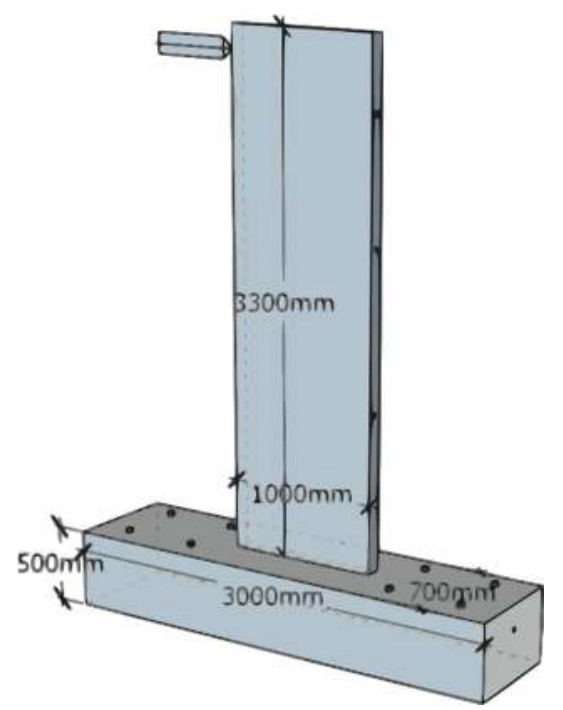

Şekil 1. Deney numunesinin genel görünümü ve boyutları

Kompozit perde duvar üzerindeki yüklemelerde kuvvet kontrollü ve deplasman kontrollü protokoller uygulanmıştır. Deney elemanına çevrimsel yüklemeler quasi-statik yükler olarak sisteme etki ettirilmiştir. Perde duvarda eğilme davranışı $120 \mathrm{kN}$ yük seviyesine kadar devam etmiştir. $\mathrm{Bu}$ seviyede numune tepe noktası yerdeğiştirmesi $11 \mathrm{~mm}$ olarak ölçülmüştür. $\mathrm{Bu}$ aşamadan sonra yapısal elemanda diyagonal çatlaklar belirginleşmeye başlamıştır. Eğilme davranışından kesme davranışına $180 \mathrm{kN}$ yük seviyesinde geçiş başlamıştır. Yapıda kesme çatlakları arttıkça yapının yük taşıma kapasitesi gittikçe azalmış ve $202 \mathrm{kN}$ yük seviyesinde maksimum yüke ulaştıktan sonra yapı perde uç bölgelerindeki kabuk betonları dökülmeye başlamıştır. İleri ki deplasman protokollü adımlarda çelik levha elemanlarında burkulmalar meydana gelmiştir. Son deplasman 65 mm olarak belirlenmiştir (Şekil 3).

\section{Sayısal Çalışma}

$\mathrm{Bu}$ çalışmanın ikinci aşamasında kompozit betonarme perde duvarın sayısal modeli OpenSees (Open System for Earthquake Engineering Simulation) [13] programı kullanılarak oluşturulmuş ve monotonik yatay yük etkisi altındaki davranışı incelenmiştir. Betonarme kompozit perde duvarın sonlu eleman modeli, OpenSEES kütüphanesinde yer alan "dispBeamColumn" deplasman tabanlı kiriş-kolon elemanı kullanılarak çubuk eleman olarak modellenmiştir. OpenSees programında kompozit perde duvarın doğrusal olmayan davranışı "lif" (fiber) yaklaşımıyla eleman uzunluğu boyunca yayılı olarak tanımlanmıştır. Betonarme kompozit perde duvardaki çelik saç levha, çelik donatı, sargılı ve sargısız beton malzeme modelleri OpenSees kütüphanesinde bulunan malzeme modelleri yardımıyla tanımlanmıştır. Çelik saç levha ve çelik donatı "Stee101" malzeme modeli, sargısız ve sargılı beton malzemeleri ise sırasıyla "Concrete01" ve "Concrete04" malzeme modelleri ile tanımlanmıştır (Şekil 2). 


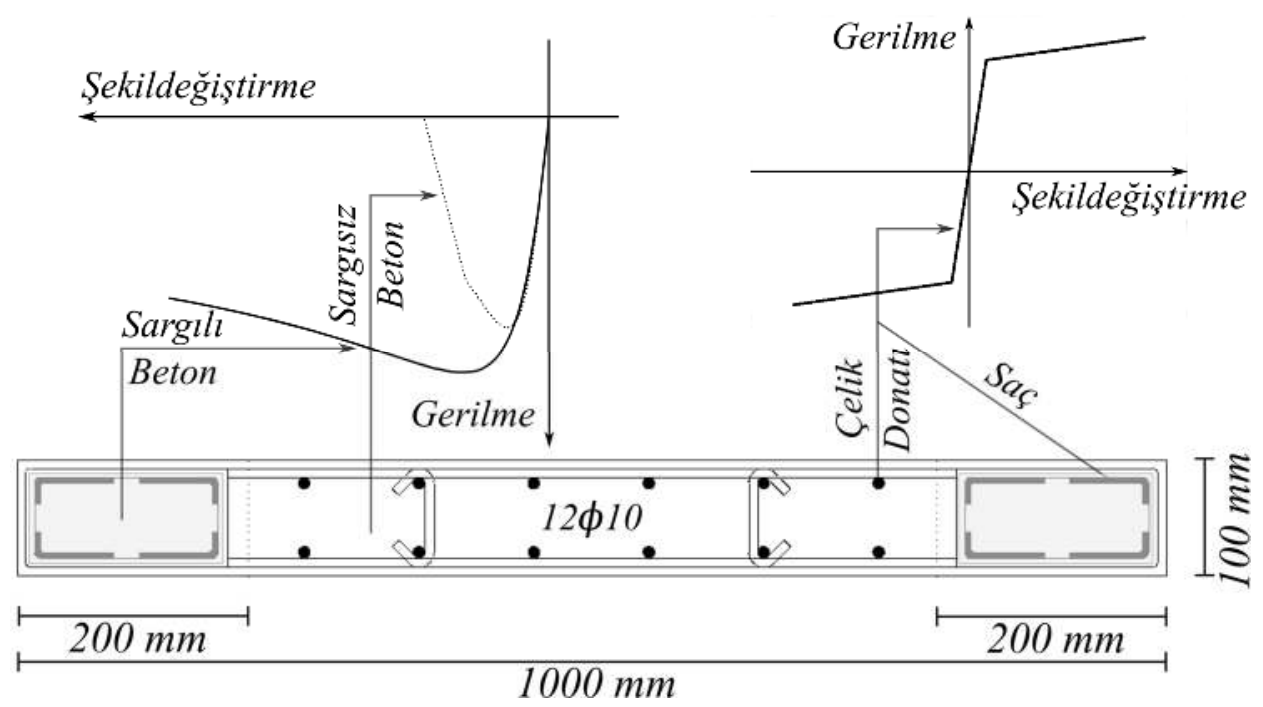

Şekil 2. Betonarme kompozit perde duvar kesiti ve malzeme modelleri

OpenSees sonlu eleman modelinin performansını belirlemek amacıyla monotonik yükleme etkisi altındaki sonlu eleman modeli sonucu ile tekrarlı yük etkisi altındaki betonarme kompozit perde duvarın deneysel sonucu karşılaştırılmıştır (Şekil 3). Şekil 3'den de açıkça görüldüğü gibi betonarme kompozit perde duvarın davranışını gerçekçi bir şekilde modellemede sonlu eleman modeli oldukça başarılıdır.

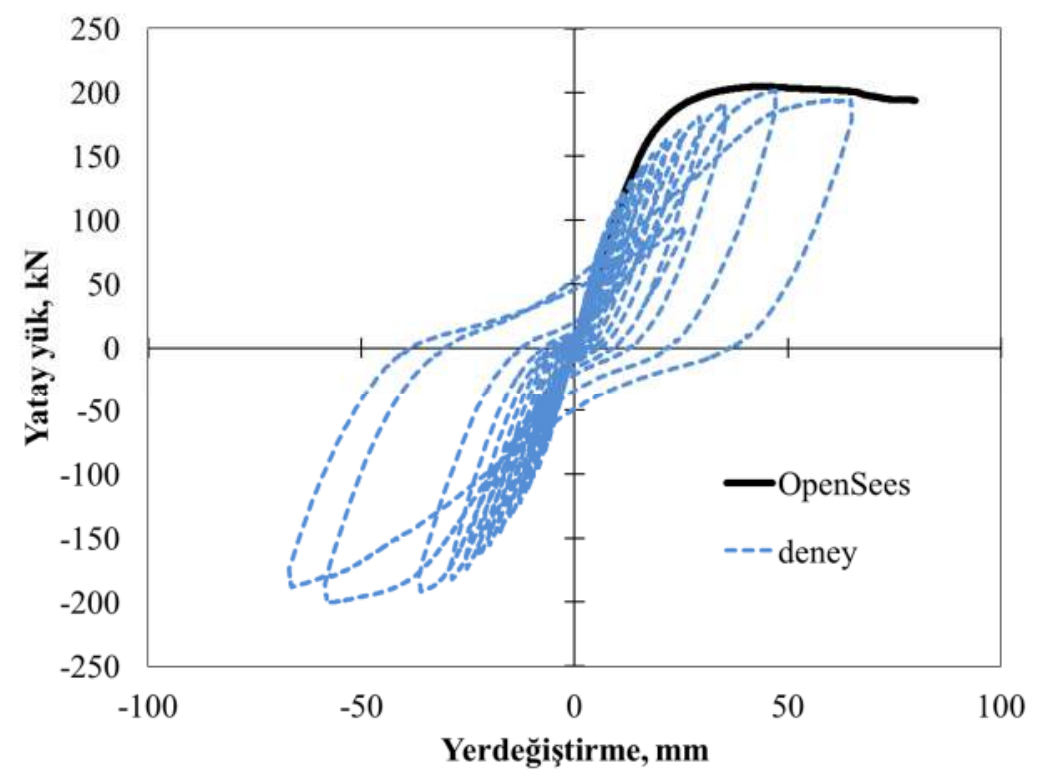

Şekil 3. OpenSees sonlu eleman modelinin performans1 


\section{Parametrik Çalışma}

Deneysel sonuçlar ile doğrulanmış sonlu eleman modeli kullanılarak bir parametrik çalışma yapılmıştır. Parametrik çalışmada eleman boyutları, donatı özellikleri ve konfigürasyonu, beton malzemesi gibi parametreler sabit tutulmuş sadece saç çelik levhanın malzeme özellikleri ve kalınlığı değiştirilmiştir (Tablo 1).

Tablo 1. Parametrik çalışmada kullanılan değişkenler

\begin{tabular}{|c|c|c|c|}
\hline Beton & \multicolumn{2}{|c|}{ Saç Levha } & \multirow{2}{*}{ Analiz } \\
\hline $\begin{array}{c}\mathrm{f}_{\mathrm{c}} \\
(\mathrm{MPa})\end{array}$ & $\begin{array}{c}\mathrm{t} \\
(\mathrm{mm})\end{array}$ & $\begin{array}{c}\text { fy } \\
(\mathrm{MPa})\end{array}$ & \\
\hline \multirow{3}{*}{25} & \multirow{3}{*}{5} & 270 & Deneysel \\
\cline { 2 - 3 } & & 350 & \\
\cline { 2 - 3 } & \multirow{2}{*}{7} & 420 & $\begin{array}{c}\text { OpenSees Sonlu Eleman } \\
\text { Modeli }\end{array}$ \\
\cline { 2 - 3 } & & 350 & \\
\cline { 2 - 3 } & & 420 & \\
\hline
\end{tabular}

Betonarme kompozit perde duvar sonlu eleman modellerinin yatay yük etkisi altındaki doğrusal olmayan analizleri OpenSees programı yardımıyla çözülmüş ve analiz sonuçları Şekil 4-5 te sunulmuştur. Çelik saç levhanın malzeme dayanımlarının betonarme kompozit perde duvar davranışına etkileri iki farklı çelik saç levha kalınlığı için Şekil 4'te sunulmuştur. Şekil 4 'ten de açıkça görüldüğü gibi çelik saç levha kalınlığının artması durumunda malzeme dayanımının davranışa etkileri daha belirgindir. Saç levha malzeme dayanımın $270 \mathrm{MPa}$ dan $420 \mathrm{MPa}$ çıması durumunda yatay yük taşıma kapasitesindeki iyileşme levha kalınlığ $\mathrm{t}=5 \mathrm{~mm}$ iken \%14,37 ve $\mathrm{t}=7 \mathrm{~mm}$ iken ise \%38.72 civarlarında olmaktadır. Dolayısıyla hem malzeme dayanımı hem de daha belirgin bir şekilde levha kalınlığını, betonarme kompozit perde duvarın performansını önemli seviyelerde iyileştirmektedir.

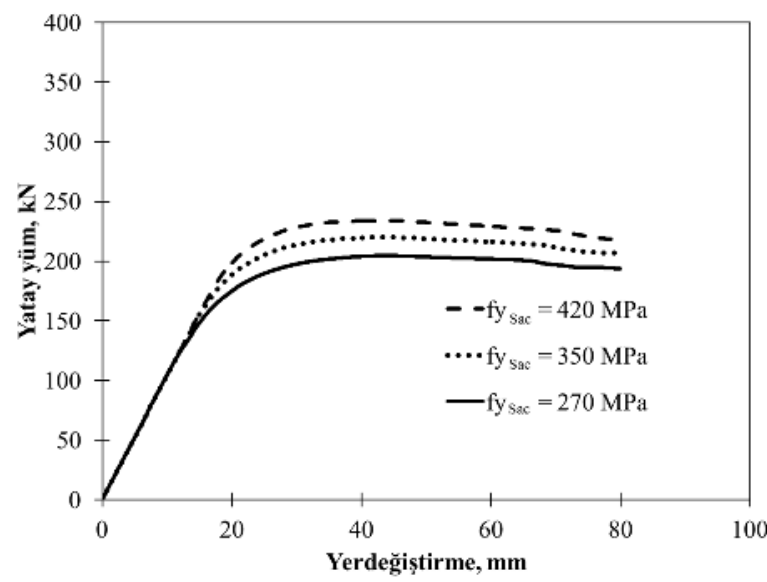

a) $\mathrm{t}=5 \mathrm{~mm}$

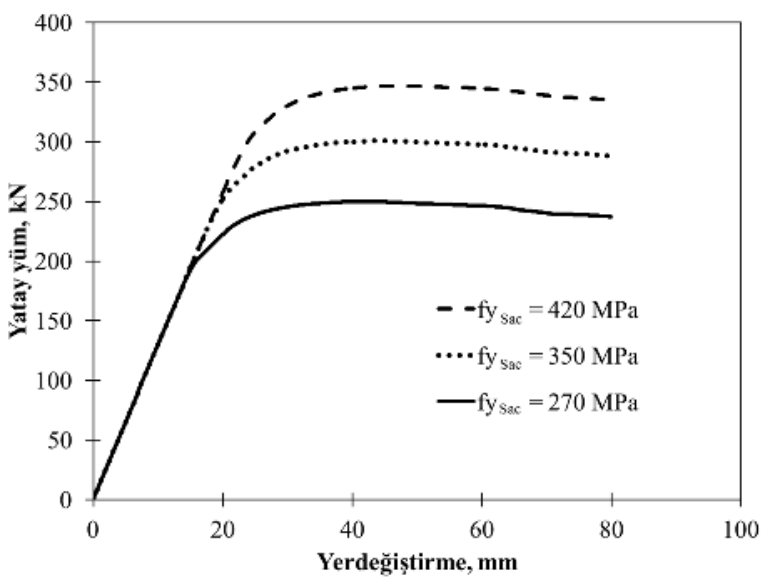

b) $\mathrm{t}=7 \mathrm{~mm}$

Şekil 4. Betonarme kompozit perde duvar davranışına saç çelik levha malzeme dayanımının etkisi 
Çelik saç levhanın kalınlığının betonarme kompozit perde duvar davranışına etkileri üç farklı çelik saç levha malzeme dayanımı için Şekil 5'te sunulmuştur. Şekil 5'ten de açıkça görüldügü gibi çelik saç levha kalınlığının perde duvarın davranışına etkileri malzeme dayanımının daha yüksek olduğu durumlarda çok daha belirgin olmaktadır. Saç levha malzeme dayanımı 270MPa iken çelik levhanın kalınlığı $\mathrm{t}=5 \mathrm{~mm}$ den $\mathrm{t}=7 \mathrm{~mm}$ çıkarılması durumunda betonarme kompozit perde duvarın yatay yük taşıma kapasitesindeki iyileşme \%38.72 civarlarında olmaktadır. Malzeme dayanımı $420 \mathrm{MPa}$ olduğu durumda ise yatay yük taşıma kapasitesindeki iyileşme $\% 48.21$ seviyelerine ulaşmaktadır.

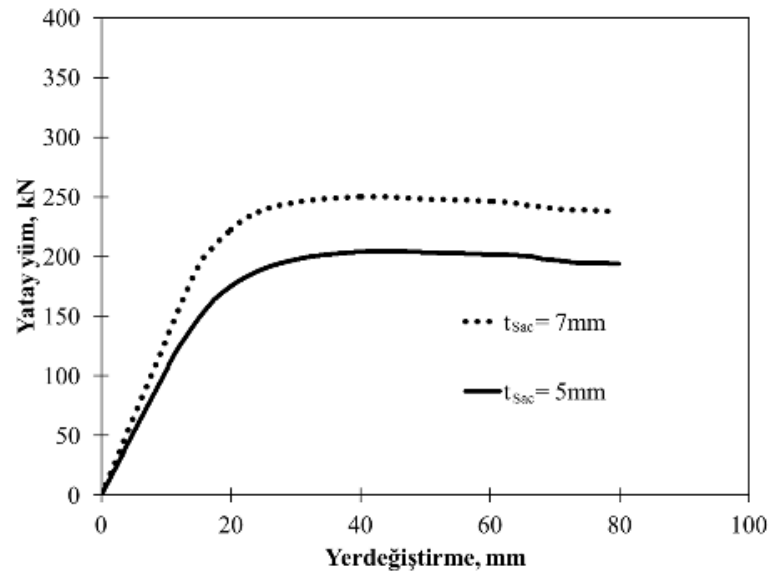

a) $\mathrm{f}_{\mathrm{y}}=270 \mathrm{MPa}$

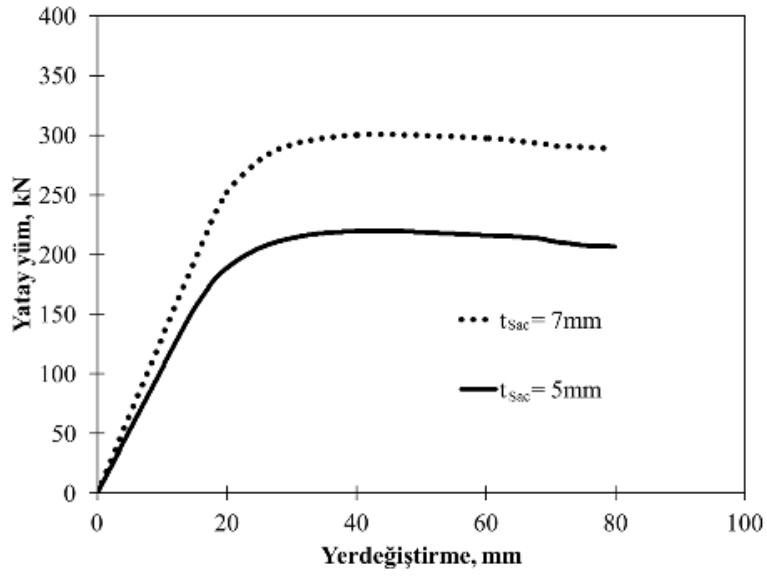

b) $\mathrm{f}_{\mathrm{y}}=350 \mathrm{MPa}$

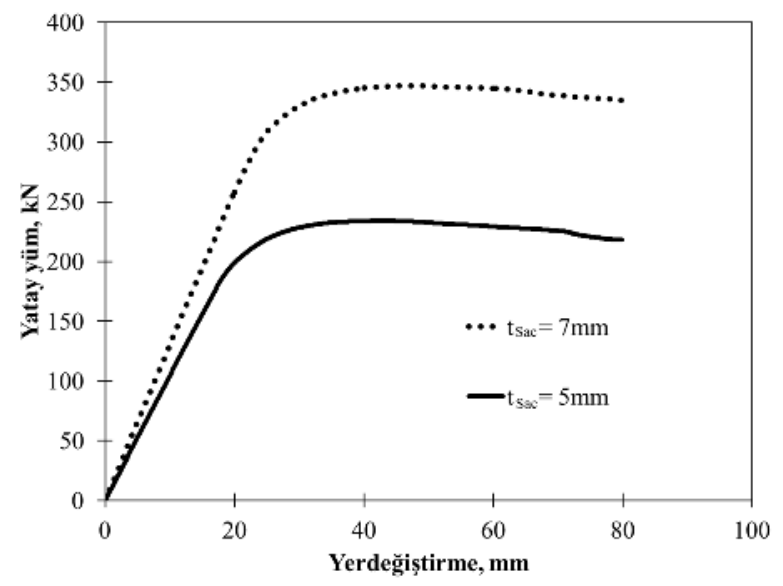

c) $\mathrm{f}_{\mathrm{y}}=420 \mathrm{MPa}$

Şekil 5. Betonarme kompozit perde duvar davranışına saç çelik levha kalınlığının etkisi 


\section{Sonuçlar}

Betonarme perde duvarlarda, perde uç bölgelerindeki yoğun donatılar sebebi ile perde duvara beton dökümü sırasında yoğun olan donatıların arasına beton tam olarak yerleşememekte, dayanım kaybı ve aderans sorunu ortaya çıkmaktadır. Alternatif olarak, perde uç bölgesinde yoğun donatı bulunan betonarme perde duvarlar yerine, perde uç bölgesinde L şeklinde yapısal çelik elemanlardan imal edilmiş kompozit perde duvarların kullanılabilme ihtimali araştırılmıştır. Perde uç bölgelerinde L şeklinde yapısal çelik elemanlar bulunan kompozit perde duvarların sismik davranışını incelemek amacıyla deneysel ve analitik bir çalışma yapıllmıştır. Bu çalışmada perde uç bölgelerinde L şeklinde yapısal çelik elemanlar bulunan 1/3 geometrik ölçekli kompozit perde duvar depremi benzeştiren tersinir tekrarlanır yatay yükler altında test edilmiş ve elde edilen sonuçlar analitik olarak doğrulanmıştır. Kompozit perde duvarın davranışını gerçekçi bir şekilde modellemede sonlu eleman modeli oldukça başarılı olmuştur. 


\section{Kaynaklar}

[1] D. Dan, A. Fabian, and V. Stoian, "Nonlinear behavior of composite shear walls with vertical steel encased profiles," Eng. Struct., vol. 33, no. 10, pp. 2794-2804, 2011.

[2] D. Dan, A. Fabian, and V. Stoian, "Theoretical and experimental study on composite steelconcrete shear walls with vertical steel encased profiles," J. Constr. Steel Res., vol. 67, no. 5, pp. 800-813, 2011.

[3] S. H. Cho, B. Tupper, W. D. Cook, and D. Mitchell, "Structural Steel Boundary Elements for Ductile Concrete Walls," J. Struct. Eng., vol. 130, no. 5, pp. 762-768, 2004.

[4] Y. Zhou, X. Lu, Z. Huang, and Y. Bo, "Seismic Behavior of Composite Shear Walls With Multi-Embedded Steel Sections. Part Ii: Analysis," Struct. Des. Tall Spec. Build., vol. 19, no. 6, pp. 637-655, 2010.

[5] L. Shahryari and M. Esfandiari, "Comparison of plasticity and stiffness of steel shear walls with composite steel plate shear wall," J. Struct. Eng. Geotech., vol. 5, no. 3, pp. 21-26, 2015.

[6] J. Qian, Z. Jiang, and X. Ji, "Behavior of steel tube-reinforced concrete composite walls subjected to high axial force and cyclic loading," Eng. Struct., vol. 36, pp. 173-184, 2012.

[7] N. H. Nguyen and A. S. Whittaker, "Numerical modelling of steel-plate concrete composite shear walls," Eng. Struct., vol. 150, pp. 1-11, 2017.

[8] F. Y. Liao, L. H. Han, and Z. Tao, "Performance of reinforced concrete shear walls with steel reinforced concrete boundary columns," Eng. Struct., vol. 44, pp. 186-209, 2012.

[9] F. Y. Liao, L. H. Han, and Z. Tao, "Seismic behaviour of circular CFST columns and RC shear wall mixed structures: Experiments," J. Constr. Steel Res., vol. 65, no. 8-9, pp. 1582-1596, 2009.

[10] H. S. Hu, J. G. Nie, J. S. Fan, M. X. Tao, Y. H. Wang, and S. Y. Li, "Seismic behavior of CFST-enhanced steel plate-reinforced concrete shear walls," J. Constr. Steel Res., vol. 119, pp. 176-189, 2016.

[11] A. Ali, D. Kim, and S. G. Cho, "Modeling of nonlinear cyclic load behavior of I-shaped composite steel-concrete shear walls of nuclear power plants," Nucl. Eng. Technol., vol. 45, no. 1, pp. 89-98, 2013.

[12] M. H. Kisa, S. B. Yüksel, and N. Caglar, "An Experimental Study on the Hysteric Behavior of Composite Shear Walls," 4th Int. Symp. Innov. Technol. Eng. Sci. ISITES2016, vol. 2016, no. November, 2016.

[13] McKenna, F., Fenves G. L. and Scott, M. H. (2004), Open system for earthquake engineering simulation, Pacific Earthquake Engineering Research Center, University of California, Berkeley, http://opensees.berkeley.edu. 